\title{
PELATIHAN PEMBUATAN BAHAN AJAR UNTUK SISWA SEKOLAH DASAR MUHAMMADIYAH XI PALEMBANG BERBASIS MULTIMEDIA
}

\author{
Evi Yulianti1), Dona Marcelina2) \\ 1)Program Studi Sistem Informasi, Universitas Indo Global Mandiri \\ 2)Program Studi Manajemen Informasi, Universitas Indo Global Mandiri \\ Jalan Jend. Sudirman No. 629 KM. 4 Palembang Kode Pos 30129 \\ Email : eviyulianti@uigm.ac.id ${ }^{1}$, donamarcelina@uigm.ac.id ${ }^{2)}$
}

\begin{abstract}
ABSTRAK
Perkembangan di bidang teknologi dan ilmu pengetahuan membuat organisasi harus semakin peka dalam peningkatan kualitas sumber daya yang dimilikinya. Oleh karena itu untuk menyikapi fenomena tersebut perlu adanya tindak lanjut dari organisasi sebagai upaya agar kemampuan yang dimiliki pegawainya tidak statis akan tetapi berkembang secara dinamis. Salah satunya yaitu dengan adanya pelatihan dan workshop penggunaan internet dan multimedia sebagai penunjang kegiatan pembelajaran pada SD Muhammadiyah XI Palembang. Kegiatan pelatihan ini dimulai dengan pengenalan cara penggunaan teknolgi informasi dan komunikasi termasuk internet dan multimedia serta manfaat penggunaan multimedia yaitu Microsoft Powerpoint dalam pembuatan bahan ajar. Proses kegiatan dilaksanakan dalam waktu 3 minggu dalam satu bulan mulai dari proses persiapan hingga pembuatan laporan kegiatan. Tujuan kegiatan ini adalah mengenalkan internet dan multimedia merupakan sebuah tools yang dapat meningkatkan keterampilan dalam penggunaan komputer bagi para Guru SD Muhammadiyah XI Palembang sehingga mampu menggunakan internet untuk mencari sumber informasi serta mampu menjadikankanya bahan ajar berbentuk powerpoint .
\end{abstract}

Kata kunci : Internet, Microsoft Power Point, Tools

\section{PENDAHULUAN}

Seiring dengan perkembangan teknologi dan perubahan-perubahan dunia yang semakin hari semakin kompleks, menuntut seseorang untuk selalu menyegarkan kembali kemampuan yang dimilikinya sesuai dengan kapasitas perubahan tersebut. Membangun karir merupakan salah satu tugas perkembangan yang akan dilalui dalam kehidupan individu yang harus terus meningkatkan kemampuannya agar dapat membangun karir ataupun jabatan yang dimilikinya. Sebaliknya, suatu organisasi juga akan semakin maju dan berkembang apabila sumber daya yang dimiliki oleh pegawainya baik dan berkualitas.

Perkembangan di bidang teknologi dan ilmu pengetahuan membuat organisasi harus semakin peka dalam peningkatan kualitas sumber daya yang dimilikinya. Tak jarang pula sumber daya manusia atau pegawai yang menduduki jabatan tertentu dalam organisasi mempunyai kemampuan yang sesuai dengan persyaratan yang diperlukan. Oleh karena itu untuk menyikapi fenomena tersebut perlu adanya tindak lanjut dari organisasi sebagai upaya agar kemampuan yang dimiliki pegawainya tidak statis akan tetapi berkembang secara dinamis. Salah satunya yaitu dengan adanya Pelatihan dan workshop penggunaan Internet dan Microsoft Powerpoint sebagai penunjang kegiatan pembelajaran di SD Muhammadiyah XI Palembang. Pelatihan ini telah dilaksanakan pada tanggal 02 Agustus 2019. Dengan kegiatan ini diharapkan para guru SD Muhammadiyah XI Palembang dapat meningkatkan kreativitas terutama pada kegiatan pembelajaran yang semakin hari mengalami semakin banyak peningkatan.

\subsection{Bentuk Kegiatan}

Beberapa kegiatan yang dilakukan adalah:

a. Pelatihan pembuatan bahan ajar menggunakan Microsoft Powerpoint.

b. Pengenalan internet yang digunakan untuk mencari sumber bahan ajar serta mampu menjadikankanya bahan ajar. 


\subsection{Tempat Kegiatan}

Dilaksanakan di SD Muhammadiyah XI Jl.sriwijaya Raya Km 12 RT 38 RW 05 Kelurahan Karya Jaya Kecamatan Kertapati Palembang Kode Pos 30259.

\subsection{Waktu Kegiatan dan Materi Pokok dalam Kegiatan}

Pelaksanaan kegiatan dilakukan dalam 1 (satu) hari. Adapun jadwal pelaksanaan adalah sebagai berikut:

Tabel 1. Jadwal Pelaksanaan Kegiatan

\begin{tabular}{|c|c|c|}
\hline Tanggal Pelaksanaan & Waktu & Materi \\
\hline \multirow{2}{*}{02 Agustus 2019} & $08: 30-11: 30$ & Workshop Microsoft PowerPoint \\
\cline { 2 - 3 } & $13: 00-16: 30$ & Workshop Pengenalan Internet \\
\hline
\end{tabular}

\subsection{Durasi Waktu Pelaksanaan Pelatihan}

Durasi waktu yang dibutuhkan selama pembuatan dan pelaksanaan kegiatan pengabdian pada masyarakat tersebut adalah sebagai berikut:

Tabel 2. Durasi Waktu Pembuatan dan Pelaksanaan Kegiatan

\begin{tabular}{|c|c|c|c|}
\hline KEGIATAN & TANGGAL & WAKTU & DURASI \\
\hline $\begin{array}{l}\text { Terima Surat Pemohonan Pelatihan Guru } \\
\text { dari SD Muhammadiyah XI Palembang } \\
\text { ke Rektor Universitas Indo Global } \\
\text { Mandiri }\end{array}$ & 19 Juli 2019 & 9:00 & 1 jam \\
\hline $\begin{array}{l}\text { Rapat koordinasi kegiatan Pelatihan dan } \\
\text { workshop di SD Muhammadiyah XI } \\
\text { Palembang }\end{array}$ & 23 Juli 2019 & 09:00 - 16:00 & 7 jam \\
\hline $\begin{array}{l}\text { Terima Surat Tugas Dekan Fasilkom } \\
\text { untuk melakukan pengabdian } \\
\text { masyarakat di SD Muhammadiyah XI } \\
\text { Palembang }\end{array}$ & 26 Juli 2019 & 9:00 & 1 jam \\
\hline Pembuatan proposal kegiatan Pelatihan & 23-26 Juli 2019 & 09:00 - 12:00 & 9 jam \\
\hline $\begin{array}{l}\text { Penyerahan dan pengesahan proposal } \\
\text { kepada Dekan Fakultas Ilmu Komputer }\end{array}$ & 27 Juli 2019 & 09:00 - 10:00 & 1 jam \\
\hline Pembuatan materi ppt & 30 Juli 2019 & $08.00-16.00$ & 24 jam \\
\hline $\begin{array}{l}\text { Konfirmasi kegiatan Pelatihan di SD } \\
\text { Muhammadiyah XI Palembang }\end{array}$ & 31 Juli 2019 & 08:00 - 16:00 & 8 jam \\
\hline Persiapan pelatihan & 1 Agustus 2019 & $10: 00-12: 00$ & 2 jam \\
\hline $\begin{array}{l}\text { Pelatihan pertemuan I oleh } \quad \text { Dona } \\
\text { Marcelina, M.Kom }\end{array}$ & 02 Agustus 2019 & $08.30-11.30$ & $3 \mathrm{Jam}$ \\
\hline $\begin{array}{l}\text { Pelatihan pertemuan II oleh oleh Evi } \\
\text { Yulianti }\end{array}$ & 02 Agustus 2019 & $13.00-16.30$ & 3 Jam \\
\hline $\begin{array}{l}\text { Penyerahan Kenangan dan foto bersama } \\
\text { dengan para guru SD Muhammadiyah XI } \\
\text { Palembang }\end{array}$ & 02 Agustus 2019 & $11.30-12.00$ & 30 Menit \\
\hline 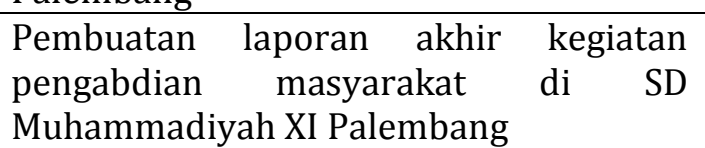 & $\begin{array}{l}\text { 5-6 Agustus } \\
2019\end{array}$ & $13.00-17.00$ & 8 jam \\
\hline
\end{tabular}




\begin{tabular}{|c|c|c|c|}
\hline 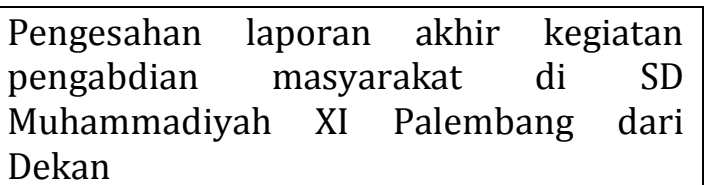 & 10 Agustus 2019 & $09.00-10.00$ & 1 jam \\
\hline $\begin{array}{l}\text { Penyerahan dan pengesahan laporan } \\
\text { pengabdian masyarakat di SD } \\
\text { Muhammadiyah XI kepada Ka. LP2MKPB }\end{array}$ & 14 Agustus 2019 & $10.30-11.30$ & $1 \mathrm{jam}$ \\
\hline \multicolumn{3}{|c|}{ Total Durasi Pelaksanaan pengabdian } & $69.5 \mathrm{jam}$ \\
\hline
\end{tabular}

Total durasi pelaksanaan pengabdian pada masyarakat untuk masing-masing pelaksana adalah: Tabel 3 Total Durasi Pelaksanaan Kegiatan

\begin{tabular}{|c|c|c|c|c|}
\hline NO & NIDN/NPM & NAMA & STATUS & $\begin{array}{c}\text { JUMLAH } \\
\text { DURASI }\end{array}$ \\
\hline 1 & 0217039102 & Dona Marcelina, M.Kom & Dosen/Narasumber & 68 jam \\
\hline 2 & 1003077602 & Evi Yulianti, M.S.I & Dosen/Narasumber & 68 jam \\
\hline 3 & 2018210119 & Muhammad Ar-Razzaq & Mahasiswa/Asisten & 20 jam \\
\hline 4 & 2018210093 & Dyah Laras Pramesti & Mahasiswa/Asisten & 20 jam \\
\hline
\end{tabular}

\subsection{Landasan Teori}

\subsubsection{Pembelajaran}

Belajar adalah sebuah proses perubahan di dalam kepribadian manusia dan perubahan tersebut ditampakkan dalam bentuk peningkatan kualitas dan kuantitas tingkah laku seperti peningkatan kecakapan, pengetahuan, sikap, kebiasaan, pemahaman, keterampilan daya pikir, dan kemampuankemampuan yang lainnya.

Berikut ini adalah pengetahuan dan definisi belajar menurut beberapa ahli: Belajar (Slameto, 2003) adalah suatu proses usaha yang dilakukan seseorang untuk memperoleh suatu perubahan tingkah laku yang baru secara keseluruhan, sebagai hasil pengalamannya sendiri dalam interaksi dengan lingkungannya. Sedangkan Belajar menurut (Trianto, 2010) adalah proses belajar terjadi melalui banyak cara baik disengaja maupun tidak disengaja dan berlangsung sepanjang waktu dan menuju pada suatu perubahan pada diri pembelajar.

Pendapat (Ngalim Purwanto, 1992) Belajar adalah setiap perubahan yang relative menetap dalam tingkah laku, yang terjadi sebagai suatu hasil dari latihan atau pengalaman. (Sri Mulyani dan Winda Anggraeni, 2016).

\subsubsection{Multimedia}

Multimedia sebenarnya adalah suatu istilah generik bagi suatu media yang menggabungkan berbagai macam media baik untuk tujuan pembelajaran maupun bukan. Keragaman media ini meliputi teks, audio, animasi, vidio, bahkan simulasi. (Tay,2000) memberikan definisi multimedia sebagai :kombinasi teks, grafik, suara, animasi dan video.

\subsubsection{Internet}

Internet adalah sebuah jaringan yang menghubungkan komputer satu sama lain yang menggunakan standar sistem global Transmission Control Protocol atau Internet Protocol Suite (TCP/IP) sebagai protokol pertukaran sehingga kita bisa saling berkomunikasi, berinteraksi, dan saling bertukar informasi meski dalam jarak yang jauh.

\section{TARGET DAN LUARAN}

\subsection{Target}

Target yang ingin dicapai dari kegiatan program pengabdian masyarakat di SD Muhammadiyah XI Palembang adalah sebagai berikut :

1. Dapat meningkatkan $80 \%$ minat para guru SD untuk mencari tambahan informasi bahan ajar dari internet. 
2. Mampu meningkatkan keterampilan para guru SD $80 \%$ dalam hal penggunan mesin pencarian google, tata cara mendownload materi atau artikel dan video pembelajaran.

3. Kemudian dari pelatihan ini dapat meningkatkan kreativitas guru $80 \%$ dalam membuat bahan ajar berbasis multimedia menggunkan berbentuk power point .

\subsection{Luaran}

Target luaran dari Pelatihan Pembuatan Bahan Ajar untuk Siswa Sekolah Dasar Muhammadiyah XI Palembang Berbasis Multimedia yaitu :

1. Para guru sangat antusias selama mengikuti sesi penyampaian materi dengan munculnya beberapa pertanyaan terkait informasi bahan ajar dari internet mencapai target $80 \%$.

2. Para guru memahami tentang cara mengunakan internet dan melakukan penelurusan bahan ajar melalui internet (https://www.google) sekitar $68 \%$.

3. Para guru SD mampu menyelesaikan tugas membuat bahan ajar berbasis multimedia menggunkan powerpoint sekitar $70 \%$.

4. Laporan Akhir hasil pengabdian kepada masyarakat akan dipublikasikan pada junal ABDIMAS UIGM

\section{METODE PELAKSANAAN PENGABDIAN}

Kegiatan Pengabdian kepada masyarakat ini dilakukan dalam bentuk pelatihan mengenai cara menggunakan internet dan membuat bahan ajar berbasis multimedia, kegiatan pengabdian kepada masyarakat ini dilakukan selama 1 (satu) hari. Adapun kegiatannya sebagai berikut :

1. Penggunaan internet sebagai penggunaan pencarian dan penelusuran bahan ajar meliputi : bagaimana mensetting internet pada laptop, komputer dan smartphone, bagaimana web brower, bagaimana menggunakan mesin pencari google, bagaimana download materi dari internet, bagaimana download video pembelajaran.

2. Pembuatan Bahan ajar berbasis Multimedia menggunakan Powerpoint meliputi : bagaimana pembuatan bahan ajar menggunakan Powerpoint, bagaimana pembuatan video pembelajaran.

\subsection{Peserta}

Kegiatan Pengabdian kepada masyarakat ini di ikuti oleh para Guru SD Muhammadiyah XI Palembang

\subsection{Proses Kegiatan}

Proses kegiatan dilaksanakan dalam 1 (satu) kali pertemuan adalah sebagai berikut :

Tabel 4. Proses Kegiatan

\begin{tabular}{|c|c|c|}
\hline WAKTU & MATERI & FASILITATOR \\
\hline \multicolumn{3}{|c|}{ Jumat, 02 Agustus 2019} \\
\hline 07:30 - 08:00 & Registrasi & Panitia dari Mahasiswa \\
\hline $08: 00-08: 15$ & Pembukaan & $\begin{array}{l}\text { Kepala SD Muhammadiyah XI } \\
\text { Palembang Yusmerana, SP.di }\end{array}$ \\
\hline $08: 15-08: 30$ & Pembukaan & $\begin{array}{l}\text { Ketua Pelaksanaan Pengabdian } \\
\text { Masyarakat dari Universitas Indo } \\
\text { Global Mandiri }\end{array}$ \\
\hline $08: 30-11: 30$ & $\begin{array}{c}\text { Pelatihan Microsoft } \\
\text { Powerpoint }\end{array}$ & $\begin{array}{l}\text { Narasumber : Dona Marcelina, } \\
\text { M.Kom }\end{array}$ \\
\hline $13: 00-16: 30$ & Pengenalan Dasar Internet & Narasumber : Evi Yulianti, M.SI \\
\hline $16: 30-16: 35$ & Penutupan & $\begin{array}{l}\text { Ketua Pelaksanaan Pengabdian } \\
\text { Masyarakat }\end{array}$ \\
\hline
\end{tabular}




\section{HASIL DAN PEMBAHASAN}

Berdasarkan permendiknas nomor 16 tahun 2007 tanggal 4 mei 2007 tentang Standar kualifikasi akademik dan kompetensi guru adalah memanfaatkan teknologi informasi dan komunikasi (TIK), termasuk internet dan multimedia untuk kepentingan pembelajaran. Internet merupakan sumber belajar yang dapat menyediakan berbagai macam informasi, sedangkan teknologi multimedia memungkinkan penyampaikan informasi secara lebih efektif dan interaktif.

Melalui pelatihan ini diharapkan dapat meningkatkan keterampilan dan pengetahuan guru-guru sekolah dasar dalam hal penggunaan internet dan pembuatan bahan ajar berbasis multimedia.

\subsection{Penyampaian Materi Pelatihan}

Materi yang akan disampaikan dalam pengabdian kepada masyarakat ini akan dilaksanakan selama 1 (satu) hari yang dilaksanakan pada tanggal 02 agustus 2019 berupa penyampaian materi, pratikum Microsoft Powerpoint dan pengenalan dasar internet berserta pratikumnya.

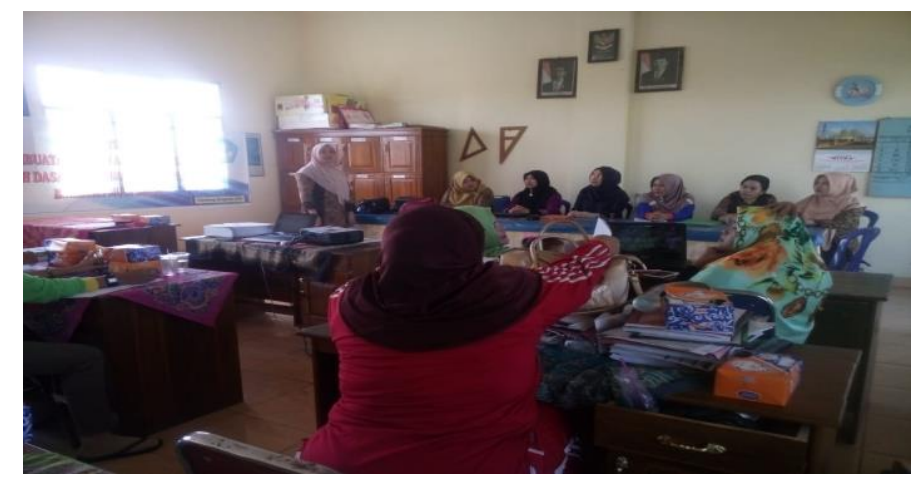

Gambar 1. Pembukaan Acara Pelatihan Pembuatan Bahan Ajar

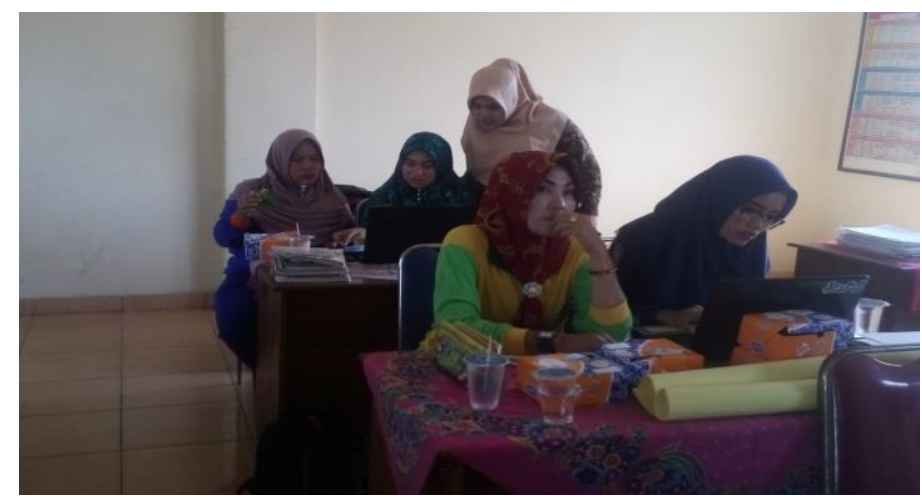

Gambar 2. Pengenalan MS. Power Point

Pada pelatihan tanggal 02 agustus 2019 sesi ke-1, perserta pelatihan di tugaskan untuk membuat contoh bahan ajar yang sudah disediakan oleh narasumber mengunakan microsoft powerpoint.

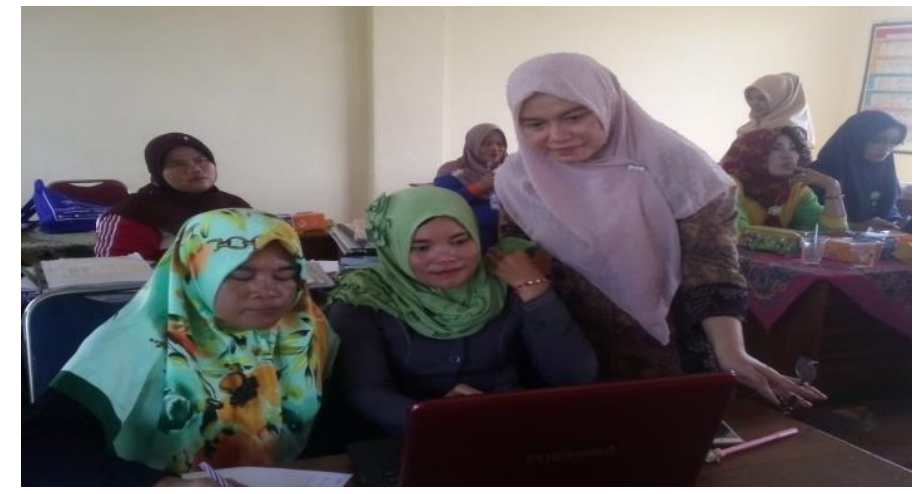

Gambar 3. Pelatihan MS. Power Point 


\subsection{Pengenalan Internet}

Pada sesi ke-2 para perserta pelatihan diberikan tugas untuk mencari sumber bahan ajar dari Internet baik yang akan mereka didownload berupa artikel, pelajaran, materi pengajaran, gambar atau video yang akan dibuat bahan ajar berbentuk powerpoint.

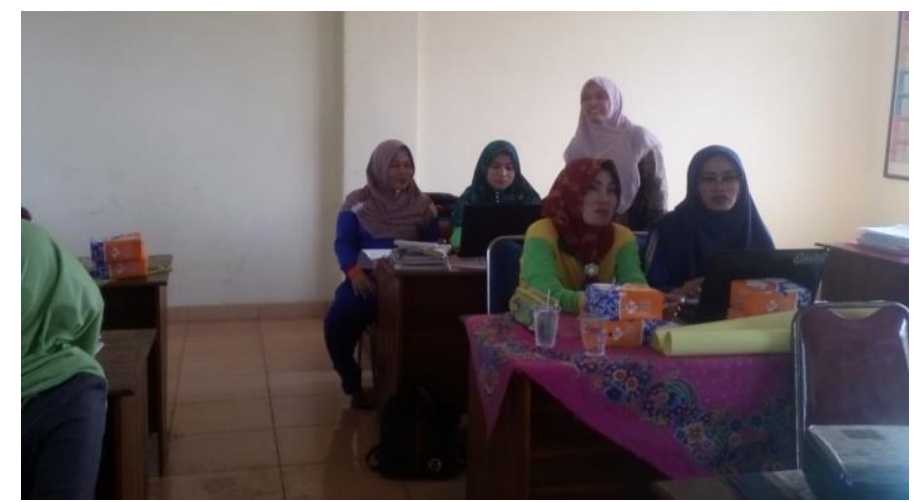

Gambar 4. Materi Pengenalan Internet

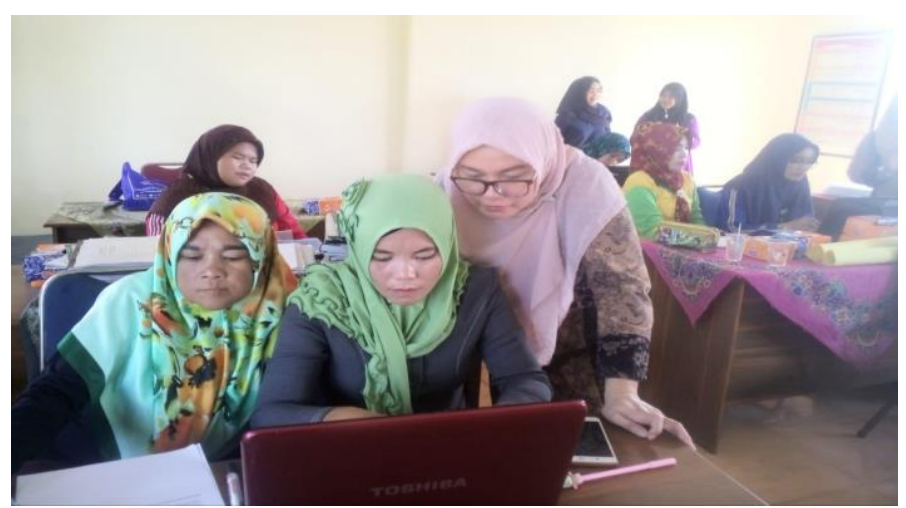

Gambar 5. Pelatihan Penggunaan mesin pencarian google
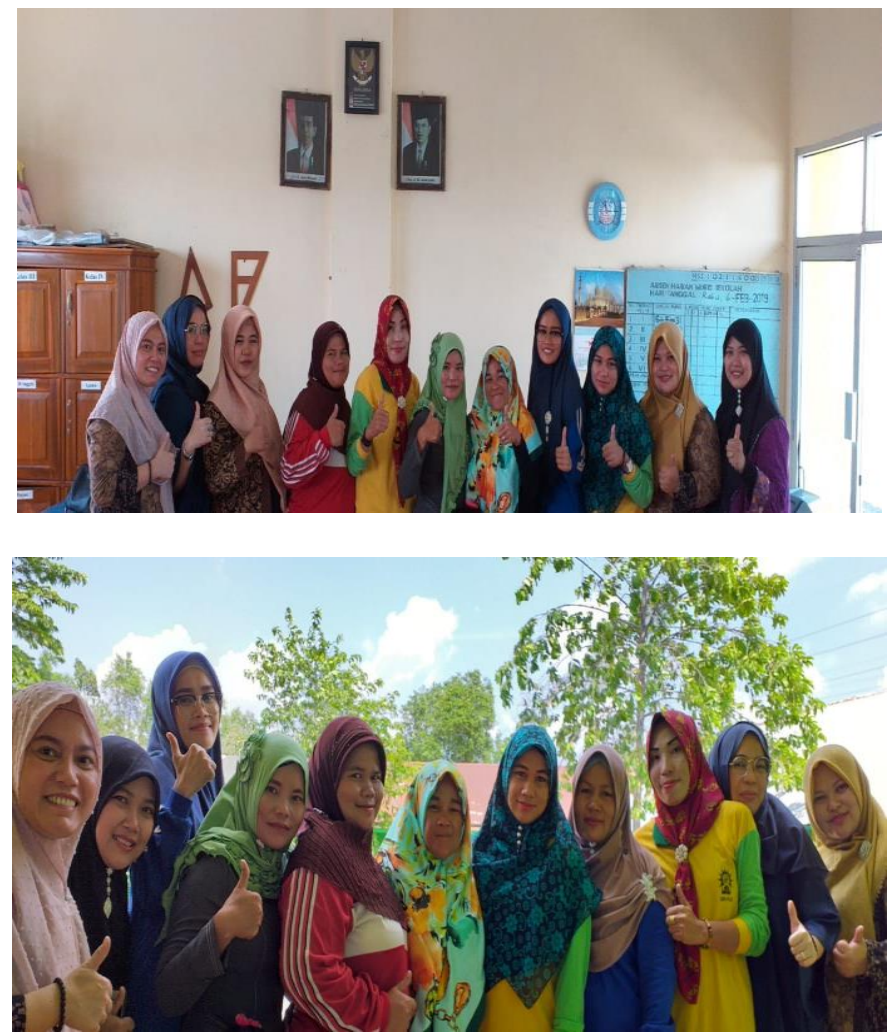

Gambar 6. Foto Bersama Peserta Pelatihan 


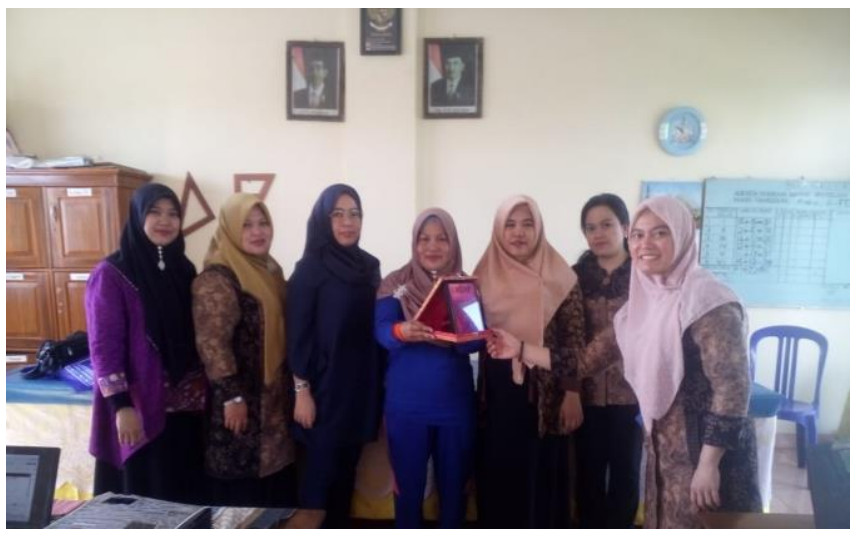

Gambar 7. Penyerahan Cinderamata Kepada Kepala Sekolah

\section{KESIMPULAN}

Pelaksanaan kegiatan pengabdian pada masyarakat dengan tema "Pelatihan Pembuatan Bahan Ajar Untuk Siswa Sekolah Dasar Muhammadiyah Xi Palembang Berbasis Multimedia” bertujuan untuk memenuhi salah satu standar kompetensi pedagodik setiap sekolah dasar ditutut untuk dapat menguasai teknologi informasi dan komunikasi (TIK) termasuk intenet dan multimedia. Kegiatan ini dapat meningkatkan minat para guru untuk mencari tambahan informasi bahan ajar dari internet, meningkatnya keterampilan guru dalam hal penggunaan komputer dari internet serta meningkatkan kreativitas guru dalam membuat bahan ajar berbasis multimedia mengunakan Microsofts PowerPoint.

Secara umum kegiatan pengabdian masyarakat ini telah berhasil dengan tercapainya luran yang diharapakan. Luaran tersebut berupa bahan ajar berbentuk power ponit yang dibuat oleh perserta pelatihan. Hasil evaluasi dari kegiatan workshop menunjukkan bahwa guru perserta pelatihan telah memahami dan mampu menggunakan internet untuk mencari sumber serta mampu menjadikankanya bahan ajar berbentuk power point.

\section{DAFTAR PUSTAKA}

Boyce, Jim. Microsoft Office Outlook 2007 Plain \& Simple. Microsoft Press, 2009.

Dahiya, S., Jaggi, S., Chaturvedi, K.K., Bhardwaj, A., Goyal, R.C. and Varghese, C., 2016. An eLearning System for Agricultural Education. Indian Research Journal of Extension Education, 12(3), pp.132-135.

Dra. Indrawati, M.Pd dan Drs. Wanwan Setiawan, M.M, Pembelajaran Aktif, Kreatif, Efektif, Dan Menyenangkan Untuk Guru SD, (Pusat Pengembangan dan Pemberdayaan Pendidik dan Tenaga Kependidikan Ilmu Pengetahuan Alam (PPPPTK IPA) untuk Program Bermutu, 2009).

English, Bill. Microsoft Office SharePoint Server 2007 Administrator's Companion. Microsoft press, 2007.

Finkelstein, Ellen. How to do everything with Microsoft Office PowerPoint 2007. McGraw-Hill, Inc., 2006.

Frandsen, Torben Lage. Microsoft Office Powerpoint. Bookboon, 2011.

Kuriakose, Somy. "Introduction to MS Office". 2016: 145-162.

Muhammad, S., 2014. Efektivitas Pembelajaran Media E-Learning Berbasis Web Dan Konvensional Terhadap Tingkat Keberhasilan Belajar Mahasiswa (Studi Kasus Mahasiswa Fakultas Ekonomi Universitas Bina Darma Palembang). SNASTIKOM 2014,

Prawiradilaga, Dewi Salma. Mozaik Teknologi Pendidikan. Jakarta: TP UNJ-Kencana, 2013.

Reed, Derek D., and Mark Dixon. "Using Microsoft Office Excel® 2007 to conduct generalized matching analyses." Journal of Applied Behavior Analysis 42.4 2009: 867-875.

Rohmah, L., 2016. Konsep E-Learning Dan Aplikasinya Pada Lembaga Pendidikan Islam. An-Nur, 3

Russinovich, Mark E., David A. Solomon, and Jim Allchin. Microsoft Windows Internals: Microsoft Windows Server 2003, Windows XP, and Windows 2000. Vol. 4. Redmond: Microsoft Press, 2005.

Shelly, Gary, and Misty Vermaat. Microsoft Office 2010: Introductory. Nelson Education, 2010. 